\title{
Exploring the Decision Making Processes of Early Career Strength and Conditioning Coaches
}

\author{
P.W. Downes ${ }^{a}$, D. Collins ${ }^{a, *}$ \\ a Moray House School of Education and Sport, University of Edinburgh, Edinburgh, EH8 8AQ, Scotland \\ *Corresponding Author Email: Dave.Collins@ed.ac.uk \\ DOI: https://doi.org/10.34256/ijpefs21210
}

Received: 15-05-2021, Revised: 21-06-2021; Accepted: 22-06-2021; Published: 23-06-2021

\begin{abstract}
The role of Strength and Conditioning coaches within sporting environments is growing in importance and more attention is being directed towards acknowledging the characteristics and decision making processes of these coaches. To date, most of the research has been with experienced coaches thus created a need to better understand those coaches at the early stages of their career. The present study utilised Applied Cognitive Task Analysis to elicit knowledge from eight strength and conditioning coaches with less than three years full time experience. Methods applied identified that less experienced strength and conditioning coaches operate in predominately stable conditions and feel comfortable delivering within this stability. Interviews revealed early career coaches to prioritise movement qualities and rely on previously acquired theoretical knowledge to make predetermined decisions on training content and responses within environments. A final theme generated demonstrated that connections with athletes were important for coaches to feel confident within their role. Implications for future coach development materials exploring the use of metacognition and its associated components of planning, monitoring and evaluation discussed.
\end{abstract}

Keywords: Environmental stability, Coach preparation, Metacognition, Coaches' awareness

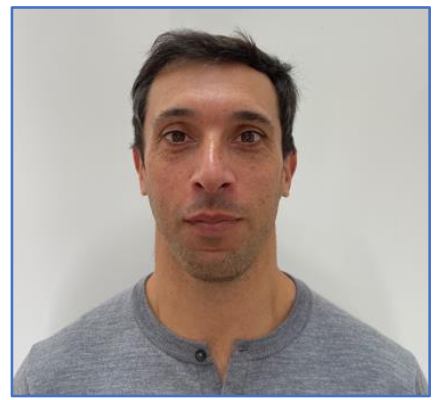

Paul Downes is the Athletic Performance Director at Auckland Rugby in New Zealand. $\mathrm{He}$ is a PhD candidate at the University of Edinburgh and is an accredited Strength and Conditioning Coach with the UKSCA and ASCA. Within his 18 years applied coaching experience he has worked with developmental and elite athletes in both the Northern and Southern Hemispheres.

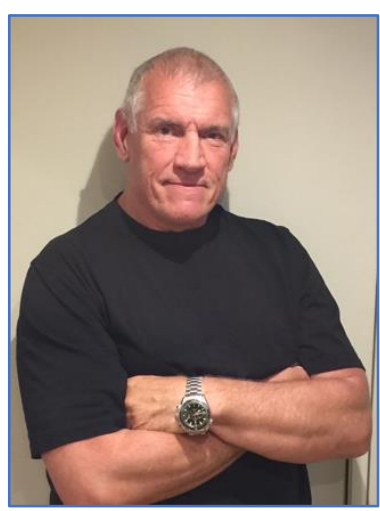

Prof. D. Collins is a Professorial Fellow at the University of Edinburgh and Director at Grey Matters Performance Ltd. As an academic, Dave has over 350 peer review publications and 80 books/chapters. As a practitioner, he has worked with over 80 World or Olympic medallists plus professional teams and performers. He has also worked as a business and organisational adviser in various fields. Dave has coached to national level in three sports, is a $5^{\text {th }}$ Dan Karate, Director of the Rugby Coaches Association, Fellow of the Society of Martial Arts and BASES, Associate Fellow of the BPS and an ex Royal Marine.

\section{Introduction}

Coaching has been described as a decision making (DM) process, where coaches draw upon sport specific and pedagogic knowledge to decide on and then apply the best methods for each coaching task [1]. In parallel, coaches draw on a broad skillset to facilitate the processes of interaction. This idea is also acknowledged in other support disciplines such as for Strength and Conditioning Coaches (SCCs). As with other coaching environments, additional traits include strong self-confidence, excellent communication skills, the ability to adapt to new situations, and a clear sense of responsibility.

This has been recently supported in the SCC setting by LaPlaca and Schemmp [2], who offered an 
empirically validated list of characteristics that differentiate expert and competent SCCs, importantly focusing on both behavioural and cognitive characteristics of expertise. Undoubtedly, knowledge on what and how to deliver is important for SCCs, but the cognitive characteristics (underpinning the why/why not) of DM for SCCs must not be overlooked. Encouragingly, research focusing on accessing the psychosocial knowledge of SCCs is also beginning to emerge $[3,4]$, although methodologies employed have so far seemed rudimentary.

To expand on the above noted research, task analysis has been used to identify how individual experts perform a cognitive task. A technique ideal for practitioners, Applied Cognitive Task Analysis (ACTA), was developed to assist the identification of the key cognitive elements required to perform a task proficiently [5]. The cognitive requirements that ACTA interviews seek to address were summarised as: difficult judgments and decisions; attentional demands; critical cues and patterns; and problem-solving strategies/other related topics [6]. In empirical work, ACTAs have been successfully used to understand expertise in a diverse range of areas, including weather forecasting [7], clinical nursing [8] and military command-and-control operations [9].

Research findings concur that SCCS at all levels of experience need to possess a high level of sport and theoretical knowledge, with experienced coaches being more versatile in the application of this knowledge. Furthermore, emerging research surrounding the psychosocial characteristics of experienced SCCs shows the need to identify the depth and breadth of these skills in less experienced or early career coaches (ECCS). Accordingly, the purpose of the present study was to examine the cognitive characteristics underpinning the decision-making habits of ECCs using ACTA.

\section{Experimental Methods}

\subsection{Participants}

Following ethical approval, participants were recruited through criterion-based, purposeful sampling strategies [10]. To ensure those interviewed were early career coaches within S \& C coaching practice, we applied the following criteria: (a) less than 3 years of full-time coaching experience; (b) completed an undergraduate degree in Sport Science or Strength and Conditioning; and (c) held aspirations of working as a full time Strength and Conditioning coach in the future. A total of eight participants, 6 male and 2 female, were recruited. This sample exceeded the recommendation of $3-5$ participants offered by Militello and Hutton [5] as the minimum requirement for effective use of the ACTA approach. Interviewees ( $25.7 \pm 3.3$ years $)$ had experience working across a range of sports, including rugby union, rugby sevens, weightlifting, track and field, netball, soccer, cricket and swimming.

\subsection{Measures}

In the initial stages of developing the ACTA, and reflecting recommendations for good practice, four pilot ACTAs were conducted to establish and refine the foundation questions. This enabled better understanding of the duration and flow of the interviews.

\subsection{Procedures}

Each interview lasted no more than 65 minutes and was recorded using a digital voice recorder. Field notes were also taken during the interviews. Interviews commenced with a discussion about the ACTA format and some general questions regarding the ECC's career to date. The first phase of the structured interview provided an overview of the task in question, which was directed at ECC's planning process and DM on training program content. After this, ECCs identified the most cognitively demanding element of the process described. The second ACTA stage, the Knowledge Audit, utilised probes questions based on knowledge categories that characterise expertise [5]: namely, diagnosing and predicting, situation awareness, perceptual skills, developing and knowing when to apply tricks of the trade, improvising, metacognition, recognizing anomalies, and compensating for equipment limitations. Examples of probing to maintain direction included: "Is there anything else you paid attention to...? Why?", "What else might influence you here?" and "Is there other information you would have liked access to?". Enabling reflection [11], participants received a copy of their transcript and were asked about the 'completeness' and 'accuracy' of the information at each stage. Respondents were encouraged to highlight anything missing or incorrect as well as comment on the perceived benefits and limitations of the ACTA as a method of investigation.

\subsection{Analysis}

Analysis followed an inductive, reflexive thematic analysis employing the six-phase procedure outlined by Braun, Clarke, Terry, and Hayfield [12]. Both semantic and latent features of data were 
considered, using a critical realist perspective. In the first instance, the primary researcher familiarised himself with ACTA responses through a combination of listening to audio recordings, along with reading and re-reading field notes and transcriptions. During coding, time was taken to revisit initial codes and revise them accordingly. Next, codes were clustered and rechecked to determine whether the patterns described were representative of the entire data set [13]. The second author served as a critical friend throughout this process, also reviewing the coding process on a subset of data scripts. On the understanding that a theme captures something important about the data relating to the research question and represents some level of patterned response or meaning within the data set [14], four themes were identified and are presented in the results section. As part of the reporting stage, analysis of the ACTA facilitated construction of a task diagram (Figure 1) and a cognitive demands table (Table 1).
Table 1 was compiled to provide an overview of the difficult cognitive elements identified by ECCs, themes of what was difficult regarding elements identified and the cues and strategies used to overcome them.

\section{Results and Discussion}

The four themes generated from the ACTAs are discussed and supported with examples of ECC responses. Figure 1 illustrates the commonality of responses associated with training program design. Table 1 identifies the difficult cognitive elements that ECCs commonly associated with their roles and a summary of the strategies used by ECCs in response to these elements. Following consideration of the four themes, we consider the role of metacognition as a solution to the issues observed.

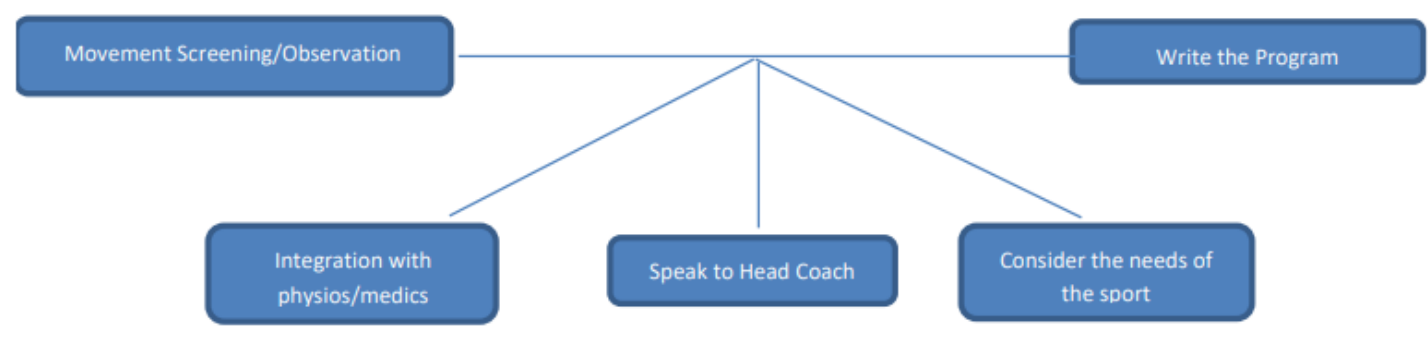

Figure 1 Task diagram representing the key stages for early career coaches in making decisions with regard to training program construction

\begin{tabular}{|c|c|c|}
\hline Difficult Cognitive Element & Primary Strategy Used & Secondary Strategy Used \\
\hline $\begin{array}{l}\text { Identifying relevant } \\
\text { considerations when establishing } \\
\text { resistance training programs }\end{array}$ & Needs of the sport considered. & $\begin{array}{l}\text { Training age/experience of the } \\
\text { athlete }\end{array}$ \\
\hline $\begin{array}{l}\text { Identification of relevant } \\
\text { variables to ensure training is } \\
\text { delivered as intended }\end{array}$ & $\begin{array}{l}\text { Look for the noticeable - } \\
\text { technical efficiency and loads } \\
\text { lifted }\end{array}$ & \\
\hline $\begin{array}{l}\text { Drawing on coaching skills to } \\
\text { deliver in the training } \\
\text { environment }\end{array}$ & Predetermined plans going in & $\begin{array}{l}\text { Deliberate Intentions of who, how } \\
\text { and what to coach - stabilise } \\
\text { environment }\end{array}$ \\
\hline $\begin{array}{l}\text { Responding to unexpected } \\
\text { changes to training environment }\end{array}$ & $\begin{array}{l}\text { Simplify the task/environment } \\
\text { Interpersonal skills to form } \\
\text { relationships and gain insights }\end{array}$ & $\begin{array}{l}\text { Adjust coaching style - instruct } \\
\text { more to gain control } \\
\text { Reclarify and/or reset expectations }\end{array}$ \\
\hline $\begin{array}{l}\text { Effectiveness of coaching } \\
\text { performance }\end{array}$ & Determine athlete satisfaction & Was technical competency shown? \\
\hline
\end{tabular}




\section{1 Comfort in Stability}

Throughout interviews, a common theme was that of ECCs creating or desiring stable conditions to operate within. Responses consistently referenced stability of DM processes relating to construction of training programs as well as their approach to role. For example, ECC 6 reported,

"... in my mind I'm sort of forming them into groups, more metabolic conditioning, who needs to work more on building a strength foundation and whose like in a good place and can work on more speed and power."

This grouping approach simplified programming decisions and assumptions made against surface level, subjective observations. Heuristics and predetermined plans (e.g., metabolic, strength or speed frameworks) are applied to athletes that satisfy the coach's criteria. The stability afforded through this framework approach was reinforced by ECC 8 who explained that they...

"would just try and hit a squat, a lunge, a push-pull, anti-rotation and anti-extension within a week".

This suggests ECCs had a template they adhered to regardless of the contexts presented.

Expert SCCs remain calm and confident when faced with adversity [2]. Furthermore, they intuitively adjust and fill any role needed to get the job at hand accomplished. This contrasts with ECC responses since uncertainty and anxiety was experienced when attempting to evaluate dynamic contexts. For example, ECC 5, who reported challenges to attention management.

"It's a bit hard with field sessions because I've just got them all at the same time so I can't really individualise it too much there. I guess I could, but I haven't really figured out a system how I'll do it without wasting time explaining things".

Ability to adapt and make increasingly intuitive decisions appears to be an area for development in ECCs, a focus for future coach preparation materials. Deliberate preparation of ECCs through trialling, testing, and reviewing approaches in varying contexts would facilitate confidence and impact, as opposed to inappropriately simplifying complex situations. Entering an applied coaching environment can be daunting, especially if the ECC has minimal background in the type of environment $[15,16]$. More focused coach preparation methods are indicated as a result.
When coaching many athletes, concerns were expressed regarding the ability to notice effectively; for example, ECC 7 explained,

"When there's only a group of five or six, I have more time to go over their technique or just talk about how we're going in terms of what loads we're doing. I can get a more quality session just because we're clearer on what we're doing and how we're doing it, rather than when we're in a big group...we don't see everything and be able to fix everything."

Throughout all stages of the ACTA, responses suggest that ECCs are unable to formulate a complete assessment of context. Consequently, effectiveness of subsequent decision(s) is reduced. The combination of an incomplete assessment coupled with a reduced appreciation for integration and communication with others lessens the impact of a session. Data suggests ECCs need to develop strategies to gather more relevant information from work contexts to make informed decisions. As LaPlaca and Schempp [2] confirmed, SCCs may be required to work with athletes of many different sports, for differing reasons, and all on the same day. As such, although ECCs may favour stable contexts, this is not a realistic expectation. Preparation material should acknowledge this so dynamic contexts can be more effectively navigated.

\subsection{Prioritising Movement Quality}

At the task diagram stage of the ACTA interviews, it was evident that ECCs had a preference to assess movement qualities to guide their DM processes (Figure 1). Indeed, only additional probing provided possible inclusion of other variables such as collaboration with others or consideration of the sport in question. Helping athletes excel at their sport is the number one priority of SCCs [2]. However, in the present study responses surrounding effective training sessions and/or programs revealed a preference towards achieving quality movements and creating adaptation through loads being lifted. Lack of reference to sport-specific transfer suggests a contrast in perceived role requirements in ECCs. This is supported in the response of ECC 5 who, when discussing their approach on the gym floor, explained they complete,

"...something like a quick, not a specific like movement screen, but using a warmup with like your basic unilateral/ bilateral lower body movement, maybe a jump as well, a landing mechanic, and then a push and a pull, just to try and assess what stage they're at." 
Using subjective, movement-driven criteria to primarily guide DM is restrictive of ECCs' DM capabilities as there are few contextual variables to consider and review against the eventual outcomes. With reference to learning, Sitkin [17] explained that being able to consider small failures is valuable in promoting risk taking, innovation and developing the capacity to adapt to changing circumstances. Lack of experimentation and wider consideration may also be due to the nature of ECCs' roles and responsibilities. For example, ECC 6 emphasised the lack of need for critical thought within their role when they stated,

"I find a lot of the time I'm just presenting other people's programs"

Within the present study, experiences were familiar and stable in the variables presented. Preferred strategies for difficult cognitive elements (Table 1) were to simplify the environment, maintain predetermined plans or adjust from relationship-based approaches to adopt more instructional style to gain control.

\subsection{Defaulting to Theory}

Expert SCCs have a strong knowledge of training and technique of movements. Importantly, however, experts are also able to apply simple and effective coaching cues to athletes. Favre [18] recommends that SCCs complete academic along with professional qualifications to provide underpinning theoretical knowledge and practical experience in sports. However, acquiring declarative or procedural knowledge is not sufficient. An example of ECCS defaulting to a set of rule-based heuristics within their DM was provided by ECC 7 in their recall of a situation.

"Within the gym we've got our main exercise set out, and then there are three or four different exercises underneath that which if an athlete can't perform exercise one, they just go down the list and hit one they can. If they can't do any of those or there's something wrong, I just send them to (Head $S$ \& $C$ coach) and he sorts that out. I'm just there to coach rather than actually implementing them."

ACTA responses highlighted that ECCs found identification of relevant variables to be a difficult cognitive task. The primary strategy identified (Table 1) was to pay attention to the athlete's technical efficiency and loads lifted; inferring a preference to recall previously learnt theoretical frameworks and consideration of bio-physical concepts. Knowledge operationalised within ECC responses was predominantly declarative in nature. However, expert SCCs apply broader knowledge sets, including psychosocial knowledge of athletes and staff, and how to optimally coach them $[2,19]$. It is plausible that, due to the nature of ECCs' roles, dynamic cognitive qualities are not required and therefore ECCs have both a low appreciation for cognitive agility and diminished abilities to be effective in less stable, high pressure environments.

\subsection{Connections Building Confidence}

Lave and Wenger [20] outlined that the most effective SCCs established an understanding and method of communication with each athlete by learning names and being clear with instruction. Communication was referred to several times in the present study but with ambiguity surrounding what constituted effectiveness. For example, ECC 5 explained,

"Like, I've always been a strong communicator but now I can communicate confidently."

Notably, examination of responses revealed connections with athletes to be orientated towards gauging levels of satisfaction and enjoyment as opposed to deeper psychosocial understanding. In the ACTA responses typically inferred participants were able to develop and sustain strong relationships. When seeking to describe the importance of connections ECC 4 said,

"I think it's probably a skill that's hard to pick up on if you don't already have it. In terms of the hard stuff like trying to get a programme to enhance the athletic performance, if you're trying to get that to go with a player you need their buy in and that respect with the athlete, and if you don't have that you're not going to get the desired outcome".

This perception of relationship building being an innate quality is problematic as ultimately implies no further development is required. It also questions the degree of self-awareness of ECCs. Both inter and intrapersonal skills have been found to be important for SCCs [21]. Given the frequency of their experiences with athletes, the need to create opportunities to develop and nurture authentic interpersonal skills in ECCS is high. Interestingly, participants' inability to recall situations involving decisions at an interpersonal level with athlete(s) and coaches highlighted a lack of experience in this area. Gilbert and Baldis [22] identified that an SCC's understanding of their own beliefs, behaviours and values is crucial in determining 
quality coaching practice and ongoing personal development. Notably, it was found that ECCS demonstrated an absence of a clear coaching philosophy. This was depicted by ECC 6 who stated,

"I think at the moment its I'm trying to figure out what strength and conditioning coach I am...as I'm working with different S\&CS picking up like how they cue and how they question and stuff so I guess I'm still figuring out what S\&C I want to be".

\subsection{Metacognition}

Against these four themes, it is important to consider what key skills are needed to develop an ECC's skillset. A recent paper, Till et al. [23] stated that SCCs need to make decisions daily for the effective implementation of their practices. In a wider context, but certainly applicable within S \& C, Jones and Wallace [24] stated that coaches' decisions are typically made based on incomplete information. The present results suggest that ECCs are not able to formulate a complete situational assessment. Consequently, ECCS need strategies to gather more relevant information from their contexts and enhance the quality of their DM.

In the absence resources within S\&C, guidance can be sought from education psychology, specifically the concept of metacognition. In an early paper, Flavell [25] suggested metacognition includes knowledge of strategy, task, and person variables. This is consistent with SCC requirements, acknowledged to include professional, interpersonal, and intrapersonal knowledge [21]. Notably, Mahdavi [26] has separated metacognition into metacognitive knowledge, metacognitive regulation, and metacognitive experiences. These components are useful when considering how to effectively develop preparation materials and experiences for SCCs particularly ECC's. ECCS are not necessarily aware of the preparation depth underpinning training session delivery by experienced others, or the experiences reflected on by these coaches in DM.

Previous research into the characteristics of both expert and competent SCCs [2] described coaches as possessing a high degree of comprehension of what to do and how to do it. At all stages of the ACTA, ECCs demonstrated a preference to rely on previously acquired declarative knowledge and theories to DM within their role without describing alternative approaches or a broad consideration of context. A third component to metacognitive knowledge is strategic knowledge which affords an individual the use of a particular strategy or tactic [27]. Present findings highlight the need and value strategic metacognitive knowledge could have in improving ECCs impact.

Metacognitive regulation addresses what the learner does about learning and has been associated with the stages of planning, monitoring and evaluation [28]. Previous literature supports the need for SCCs to be prepared and engage in planning $[18,22,23]$. Importantly, the present study identified ambiguity surrounding depth and breadth of planning within the DM processes of ECCs. Access to metacognitive regulation strategies offers development opportunities for these coaches. Similarly, ECCs can only respond to what they notice and/or monitor, although selfregulated learners will draw from varied sources and previous experiences to solve problems [29]. Results demonstrated ECCs are still developing their philosophy and coaching identity and therefore selfregulation ability is compromised. Within the Knowledge Audit, responses were primarily limited to athlete satisfaction, session flow and movement proficiency when evaluating session effectiveness. The ability to evaluate the degree of thinking after completing the task is important if ECCs are to sufficiently review and develop effective DM. Improvements in metacognitive proficiency will enable ECCs to make sense of environmental variables, both in the planning and delivery stages of coaching, and respond from a more informed selection of options.

\section{Conclusion}

Attention within the literature has been directed towards the characteristics of experienced strength and conditioning coaches. However, this paper importantly contributes evidence of the decision making characteristics of strength and conditioning coaches at the start of their career. We suggest the inclusion of metacognition, and the components of metacognitive knowledge, monitoring and evaluation, in future coaching materials: for example, within tertiary education and accreditation programs. It appears that early career coaches need greater preparation strategies to apply and review within dynamic contexts. A greater appreciation and consideration of psychosocial variables as part their decision making processes, along with their existing biophysical knowledge, will increase the early career coaches impact in their environments. 


\section{References}

[1] A. Abraham, D. Collins, R. Martindale, The coaching schematic: validation through expert coach consensus, Journal of Sports Sciences, 24 (6) (2006) 549-564. [DOI]

[2] D.A. LaPlaca, P.G. Schempp, The characteristics differentiating expert and competent strength and conditioning coaches, Research Quarterly for Exercise and Sport, 90 (3) (2020) 1-12. [DOI]

[3] C. Szedlak, B. Callary, M.J. Smith, Exploring the influence and practical development of coaches' psychosocial behaviours in strength and conditioning, Strength And Conditioning Journal, 41 (2) (2019) 8-17. [DOI]

[4] C. Szedlak, J. Batey, M. Smith, M. Church, Examining Experienced S\&C Coaches Reflections On The Effectiveness Of Psychosocial Behaviours In Coaching, International Sports Coaching Journal (2021) (ahead of print). [DOI]

[5] L.G. Militello, R.J.B Hutton, Applied cognitive task analysis (ACTA): A practitioner's toolkit for understanding cognitive task demands, Ergonomics, 41 (11) (1998) 1618-1641. [DOI] [PubMed]

[6] J. Gore, C. McAndrew, Accessing expert cognition, The Psychologist 22 (3) (2009) 218219.

[7] R.R. Hoffman \& L.G. Militello (2008) Perspectives on cognitive task analysis: Historical origins and modern communities of practice, Taylor \& Francis, New York.

[8] L.G. Militello, L. Lim, Patient assessment skills: Assessing early cues of necrotizing enterocolitis, The Journal of Perinatal and Neonatal Nursing, 9 (2) (1995) 42-52. [DOI] [PubMed]

[9] J.L Drury, E.A. Darling, "Thin-slicing" approach to understanding cognitive challenges in realtime command and control, Journal of Battlefield Technology, 11 (1) (2008) 9-16.

[10] A.C. Sparkes, B. Smith, (2014) Qualitative Research Methods in Sport, Exercise and Health: From Process To Product, Routledge, London.

[11] B. Smith, K.R. McGannon, Developing rigor in qualitative research: Problems and opportunities within sport and exercise psychology, International Review of Sport and Exercise Psychology, 11 (1) (2017) 101-12. [DOI]

[12] V. Clarke, V. Braun, G. Terry, N. Hayfield, (2019), Thematic analysis in Liamputtong, P. (Ed.), Handbook of research methods in health and social sciences (pp. 843-860). Singapore: Springer.

[13] V. Braun, V. Clarke (2012), Thematic analysis in H. Cooper, P. M. Camic, D. L. Long, A. T. Panter, D. Rindskopf, \& K. J. Sher (Eds.), APA handbook of research methods in psychology, Vol. 2: Research designs: Quantitative, qualitative, neuropsychological, and biological (pp. 57-71). Washington, DC: American Psychological Association.

[14] V. Braun, V. Clarke, Using thematic analysis in psychology, Qualitative Research in Psychology, 3 (2) (2006) 77-101. [DOI]

[15] D. Massey, Program for effective teaching: A model to guide educational programs in strength and conditioning, Strength And Conditioning Journal, 32 (5) (2010) 79-85. [DOI]

[16] C.D. Massey, M.A Maneval, Call to improve educational programs in strength and conditioning, Strength And Conditioning Journal, 36 (1) (2014) 23-27. [DOI]

[17] S.B. Sitkin (1996). Learning through failure: The strategy of small losses in M. D. Cohen \& L. S. Sproull (Eds.), Organizational learning (pp. 541578). Thousand Oaks, CA: Sage.

[18] M.W. Favre (2017). Becoming a strength and conditioning coach. National Strength and Conditioning Association. NSCA Career Series.

[19] S. Dorgo. Unfolding the practical knowledge of an expert strength and conditioning coach, International Journal of Sports Science \& Coaching, 4 (1) (2009) 17-30. [DOI]

[20] J. Lave, E. Wenger, (1991) Situated Learning Legitimate Peripheral Participation, Cambridge University Press, Cambridge.

[21] M.A. Grant, S. Dorgo, Developing Expertise In Strength And Conditioning. Strength and Conditioning Journal, 36 (1) (2014) 9-15. [DOI]

[22] W.D. Gilbert, M.W. Baldis, Becoming an effective strength and conditioning coach, Strength And Conditioning Journal, 36 (1) (2014) 28-34. [DOI]

[23] K. Till, B. Muir, A. Abraham, D. Piggott, J. Tee, A framework for decision-making within strength \& conditioning coaching, Strength And Conditioning Journal, 41 (1) (2019) 14-26. [DOI]

[24] R.L Jones, M. Wallace, Another bad day at the training ground: Coping with ambiguity in the coaching context, Sport, Education and Society, 10 (1) (2005) 119-134. [DOI]

[25] J.H. Flavell, Metacognition and cognitive monitoring. A new area of cognitive 
development inquiry, American Psychologist, 34

(10) (1979) 906-911. [DOI]

[26] M. Mahdavi, An Overview: Metacognition in Education. International Journal of Multidisciplinary and Current Research, 2 (6) (2014) 529- 535.

[27] K. Haywood, N. Getchell, Lifespan Motor Development (7th ed.). (2019) Human Kinetics.

[28] C.M. Mowling, S.K. Sims, The Metacognition Journey: Strategies for Teacher Candidate Exploration of Self and Student Metacognition, Strategies, 34 (2) (2021) 13-23. [DOI]

[29] T.K. Dail, Metacognition and coaching: How to develop a thinking athlete. Journal of Physical Education, Recreation and Dance, 85 (5) (2014) 49-51. [DOI]

\section{Funding}

No funding was received to carry out this study.

\section{Authors Contribution}

Both authors contributed equally to the intellectual content of the paper. Downes led on the design and data collection assisted by Collins. Downes also led on the writing of the paper.

\section{Conflict of interest}

The authors have no conflicts of interest to declare that they are relevant to the content of this article.

Does this article screened for similarity?

Yes.

\section{Ethics approval}

This study was approved by Institutional Ethics Committee.

\section{Informed consent}

Written consent was obtained from the participants

\section{About The License}

(c) The Author(s) 2021. The text of this article is open access and licensed under a Creative Commons Attribution 4.0 International License 